\title{
Evaluation of Calf Management and Livability in Dairy Farms in Afyonkarahisar
}

\author{
Kemal YILDIRIM ${ }^{1}$, Serdar KOÇAK ${ }^{2 *}$ \\ 1 Agriculture and Rural Development Support Institution, Afyonkarahisar Province Unit, Expert, Afyonkarahisar, Turkey \\ ${ }^{2}$ Afyon Kocatepe University Faculty of Veterinary Medicine, Department of Animal Breeding and Husbandry, ANS Campus, \\ Afyonkarabisar, Turkey
}

\begin{abstract}
This study was carried out in order to examine the factors affecting the survival of calves with rearing, feeding and management of calves in dairy cattle farms in Afyonkarahisar province. The research was conducted in 25 dairy farms in center Afyonkarahisar and districts, and used 400 head Simmental calves and 117 head Holstein calves which are birth in 7 farms which have regular records for their livability of calves in 2016 and 2017. The survival rates were $0,920 \pm 0,021,0,896 \pm 0,023,0,874 \pm 0,025$ and $0,857 \pm 0,025$ at $30,60,75$ and 90 days of life in the Simmental calves, respectively. The effects of dairy farm and birth season at 30, 60, 75 and 90 days of survival rates, effect of age of dam at 60,75 and 90 days of survival rates and effect of gender at 75 days of survival rates in the Simmental calves were significant $(\mathrm{p}<0,05 ; \mathrm{p}<0,01)$. The survival rates were $0,918 \pm 0,027,0,918 \pm 0,027$, $0,918 \pm 0,027$ and $0,893 \pm 0,029$ at 30,60,75 and 90 days of life in the Holstein calves, respectively. The effects of gender at 30, 60, 75 and 90 days for survival rates, effect of birth season at 30, 60 and 75 days of survival rates in Holstein calves were significant $(\mathrm{p}<0,05 ; \mathrm{p}<0,01)$. As a result, it was concluded that the survival rates in the Simental and Holstein calves is low in terms of optimal productivity and ideal values, and the quality and management of colostrum should be taken into consideration.
\end{abstract}

Keywords: Calf, dairy cattle, livability, management

\section{Afyonkarahisar Damızlık Süt Sığırı İşletmelerinde Buzağı Bakımı ve Yaşama Gücünün Değerlendirilmesi}

ÖZ

Bu çalışma, Afyonkarahisar İlinde bulunan damızlık süt sığııı işletmelerindeki buzağı bakımı ve yönetimi ile buzağılarda yaşama gücü ve etkileyen faktörlerin incelenmesi amacıyla yapılmıştır. Araştırma, Afyonkarahisar merkez ve ilçelerinde bulunan 25 adet damızlık süt sığırı işletmesinde yürütülmüş olup yaşama gücü için 7 adet işletmenin 2016 ve 2017 yıllarında doğan 400 baş Simental ve 117 baş Holştayn buzağısı kullanılmıştır. Simental buzağılarda yaşama gücü ortalamaları 30., 60 ., 75. ve 90 . günde sırasılya; $0,920 \pm 0,021,0,896 \pm 0,023,0,874 \pm 0,025$ ve $0,857 \pm 0,025$ olarak tespit edilmiştir. Simental buzağılarda yaşama gücüne 30., 60., 75. ve 90 . günde işletme ve doğum mevsiminin, 60., 75. ve 90. günde ana yaşının ve 75. günde ise cinsiyetin etkisinin önemli $(p<0,05 ; p<0,01)$ olduğu belirlenmiştir. Holştayn buzağılarda yaşama gücü ortalamaları 30., 60., 75. ve 90. günde sırasıly; $0,918 \pm 0,027,0,918 \pm 0,027,0,918 \pm 0,027$ ve $0,893 \pm 0,029$ olarak hesaplanmıştır. Holştayn buzağılarda 30., $60 ., 75$. ve 90 . günde yaşama gücüne cinsiyetin, $30 ., 60$. ve 75 . günde ise doğum mevsiminin etkisinin önemli ( $<<0,05$; $\mathrm{p}<0,01)$ olduğu tespit edilmiştir. Sonuç olarak, Simental ve Holştayn buzağılarda yaşama gücünün optimal verimlilik ve ideal değerler bakımından düşük olduğu, kolostrum kalitesi ve yönetimine önem verilmesi gerektiği kanaatine varılmıştır.

Anahtar Kelimeler: Buzağı, süt sığırcıllı̆̆, yaşama gücü, yönetim

To cite this article: Yuldurm K. Kogak S. Evaluation of Calf Management and Livability in Dairy Farms in Afyonkarabisar. Kocatepe Vet J. (2019) 12(3):310-316 


\section{GİRİŞ}

Sığır yetiştiriciliğinde optimum karlilık ve sürdürülebilirlik için her inekten yılda bir buzağ1 alınması ve buzağılarda yaşama gücünün yüksek olması önemlidir. Buzağılarda yaşama gücü, belli bir döneme kadar yaşayan buzağı sayısının canlı doğan hayvan sayısına bölünmesiyle hesaplanmaktadır. Doğum sonrası yaşama gücü, yeni doğan buzağıların çevre şartlarına adaptasyonunun belirlenmesinde ve işletmelerin karlılı̆̆ı açısından oldukça önemlidir (Akçapinar ve Özbeyaz 1999). Sı̆̆ırcılık işletmelerinde buzağılar bireysel veya grup halinde kapalı yâda açıkta yetiştirilmektedir. Gerek bireysel buzağ1 kulübelerinde gerekse grup buzağı alanlarında kullanılan altlıklar ve değiştirme sıklığ1 önem arz etmektedir. Buzağ1 barınaklarında zeminin kuru olması, yeterli havalandırma, hareket olanağı, yem ve su imkânı ile stressiz ortam gereklidir. Son yıllarda ahşap, plastik ve metalden buzağ1 barınakları yapılmaktadır (Özyürek ve ark. 2013).

Buzağılara zamanında, kaliteli ve yeterli kolostrum verilmesi ile büyüme, hastalık insidansı ve yaşama gücü üzerine olumlu etki yaptığ1 bildirilmektedir (Yüceer ve Özbeyaz 2010). Buzağılarda yaşama gücünü etkileyen faktörler genel olarak 1rk, besleme, iklim, hastalıklar, barınak, hijyen, doğum tipi ve cinsiyettir (Özyürek ve ark. 2013).

Buzağılarda yaşama gücünün incelendiği çalışmalarda 1 aylık yaşa kadar yaşama gücü Norveç'te \% 95,4, Fransa'da \% 93,3 ve Iran'da \% 93,51 olarak bildirilmektedir. (Gulliksen ve ark. 2009, Azizzadeh ve ark. 2012, Raboisson ve ark. 2013). Türkiye'de düzenlenen buzağı kayıpları sempozyumunda buzağılarda yaşama gücünün İtalya'da \% 75,00 (De Amicis ve ark. 2017), İngiltere'de \% 92,58 - \% 97,53 (Gates 2013), ABD'de ise \% 93,60 (APHIS 2010) olduğu ifade edilmiştir (Anonim 2017). Ayrica Türkiye'deki buzağılarda yaşama gücünün bölge ve işletmelere göre farkl1lık göstermekle beraber \% 85-90 arasında olduğu bildirilmiştir (Anonim 2017).

Türkiye'de yapılan çalışmalarda Holştayn buzağıların 30.gün, 60.gün, 75.gün ve 90.günde yaşama gücü sirasiyla; \% 93,83- 97,00; \% 93,83-94,20; \% 95,9396,34 ve \% 85,90-95,00 arasında, Simental buzağıların ise 30. ve 90 günde yaşama gücü \% 98,00 ve \%92,00$\% 98,80$ arasinda olduğu bildirilmektedir (Deliömeroğlu ve ark. 1995, Akbulut 1998, Başpınar ve ark. 1998, Karakaş 2002, Koçak ve ark. 2007, Koçak ve ark. 2008, Bayrıl ve Y1lmaz 2010, Yüceer ve Özbeyaz 2010, Ayaşan ve ark. 2016).

Bu çalışma, Afyonkarahisar ilinde bulunan damızlık süt sığırı işletmelerindeki buzağı bakımı, beslenmesi ve yönetimi bilgileri ile buzağılarda yaşama gücü ve etkileyen faktörlerin incelenmesi amacıyla yapılmıştır.

\section{MATERYAL ve METOT}

\section{Materyal}

$\mathrm{Bu}$ araştırma, Afyonkarahisar merkez ve ilçelerinde bulunan 25 adet damılık süt sı̆̆ırı işletmesinde yürütülmüştür. İşletmelerden elde edilen veriler incelenerek buzağı kayıtları düzenli olan 7 işletmede 01.01.2016-31.12.2017 arasinda doğan 400 baş Simental ve bir işletmedeki 117 baş Holştayn 1rk1 olmak üzere toplam 517 baş buzağının verileri değerlendirilmiştir.

\section{Metod}

$\mathrm{Bu}$ çalışma için işletmeler ziyaret edilerek buzağ1 bakımı, yetiştirilmesi ve ölümleri ile ilgili veriler geliştirilen forma kayıt edilmiştir. İşletmelerde sürü büyüklüğü, buzağının anasından ayrılma zamanı, kolostrumun ilk verilme zamanı, sıklığ1 ve miktarı, göbek kordonu dezenfeksiyonu ve sıklı̆̆1, buzağ1 barınak tipi, kullanılan altlığın çeşidi, miktarı ve değişim sıklığ1, suluğun çeşidi, sütten kesime kadar verilen yemlerin çeşidi, miktarı ve öğün sayısı, sütle besleme şekli (anasını emzirme, biberon, emzikli kova), sütten kesim yaş1, buzağıları izleme yöntemi, sıklı̆̆1 ve süresine ait bilgiler incelenmiştir. Buzağılarda yaşama gücünün değerlendirildiği 7 işletmede sütten kesim yaşı 60-75 gün arasındadır. Buzağılarda yaşama gücü; 30., 60., 75. ve 90. gün olmak üzere 4 dönemde değerlendirilmiştir. Haile-Mariam (1998) ve Riley ve ark. (2004)'nın bildirişleri doğrultusunda bu dönemlerde yaşayan buzağılara " 1 " ölenlere ise " 0 " kodu verilmiştir.

İstatistiki analizlerde; Simental ve Holştayn buzağılar ayrı ayrı olmak üzere işletme (1, 2, 3, 4, 5, 6 ve 7), doğum y1lı (2016 ve 2017), doğum mevsimi (sonbahar-k1ş, ilkbahar-yaz), cinsiyet (erkek ve dişi) ve ana yaşının $(2,3,4$ ve $5 \leq$ ) etkisinin belirlenmesinde variyans analizi, aralarındaki farklilık önemli bulunan grupların karşılaştırılmasında Duncan testi kullanılmıştır. Analizlerde PASW Statistics 18.0.0 programından yararlanılmıştır.

\section{BULGULAR}

\section{Buzağı Bakımı ve Yönetimi}

$\mathrm{Bu}$ araştırma kapsamında Afyonkarahisar ve ilçelerinde bulunan 25 adet damılık süt sı̆̆ırı işletmesinde Simental, Holştayn ve Esmer ırklarının bulunduğu, ağırlıklı olarak Simental 1rkının (21 işletmede) tercih edildiği ve kapasitelerinin 90-270 baş arasında olduğu belirlenmiştir. İşletmelerde düve ve ineklerin tohumlanmasinda genellikle suni tohumlamanın tercih edildiği, iki işletmenin ise boğa kullandığ1 ifade edilmiştir. Doğumdan sonra buzağıy1 anasından ayırma zamanı yirmi iki işletmede 1-3 saat içinde, iki işletmede 6-12 saat içinde, bir işletmede ise doğumdan 3 gün sonra yapıldı̆̆ı belirtilmiştir. İşletmelerde kolostrumun doğumdan sonraki ilk 1-2 saat içinde, 3 gün süreyle günde 2-3 litre olmak üzere 

göbek kordonu dezenfeksiyonu ilki doğumdan sonraki 3 saat içerisinde olmak üzere 3 gün süreyle günde 2 kez yapıldığ1 bildirilmiştir. İncelenen işletmelerde buzağı barınakları genellikle seyyar buzağ kulübesi (22 işletme), üç işletmede ise bireysel kapalı bölmeler şeklindedir. Buzağı barınaklarında kullanılan altlık, sap (19 işletme), odun talaşı (2 işletme) ve 1zgaralı sistemdir (4 işletme). Buzağ1 bölmelerinde kullanılan altlı̆̆ın değişim sıklığının genellikle 3 günde bir kez, bir işletmede haftada bir kez, bir işletme ise ayda bir kez yapıldığı ifade edilmiştir. Buzağıların sütle beslenmesinde üç ișletmenin sadece süt, diğerlerinin ise sütün yanında kesif ve kaba yem verdiği belirlenmiştir. Sütle besleme döneminde verilen besinin öğün sayısı genellikle iki olup sadece bir işletmede 3 ögündür. Sütle besleme süresinin ziyaret edilen yirmi beş işletmenin on sekizinde 60-75 gün, yedi işletmede ise 90 gün olduğu tespit edilmiștir. İşletmelerde suluk olarak kulübe suluğu, sütle besleme için ise biberon kullanılmaktadır. Buzağıların takibi, on işletmede gözlem ve kamera birlikte, on beş işletme ise sadece gözlem yoluyla yapılmaktadır. İsletmelerde aydınlatma amacıyla projektör, floresan ve LED kullanıldığı belirlenmiştir.

Buzağılarda Yaşama Gücü ve Etkileyen Faktörler Afyonkarahisar merkez ve ilçelerde bulunan Simental ve Holştayn buzağılarda yaşama gücüne ait ortalamalar ve standart hataları Tablo 1 ve 2' de sunulmuştur. Ayrica 30., 60., 75. ve 90. günde Simental ve Holştayn buzağıların yaşama gücü genel ortalamaları Şekil 1'de verilmiştir.

$\mathrm{Bu}$ çalsşmanın yürütüldüğ̈̈ işletmelerde bulunan Simental buzağılarda 30., 60., 75. ve 90. günde yaşama gücü genel ortalamas1 sirasiyla; \% 92,0; \% 89,6; \% 87,4 ve $\% 85,7$ olarak hesaplanmıştır. Simental buzağılarda yaşama gücüne 30 . günde işletme ve doğum mevsiminin, 60. günde işletme, doğum mevsimi ve ana yaşının, 75. günde işletme, doğum mevsimi, cinsiyet ve ana yaşının, 90. günde işletme, doğum mevsimi ve ana yaşının etkisinin önemli $(\mathrm{p}<0,05 ; \mathrm{p}<0,01)$ olduğu tespit edilmiştir.

Holştayn buzağılarda yaşama gücü genel ortalamaları 30., 60., 75. ve 90 . günde sirasiyla; $\% 91,8 ; \% 91,8 ; \%$ 91,8 ve $\% 89,3$ olarak tespit edilmiştir. 30., 60. ve 75 . gündeki yaşama gücüne cinsiyet ve doğum mevsimi faktörünün etkisi önemli ( $\mathrm{p}<0,05 ; \mathrm{p}<0,01)$, doğum yll ve ana yaşının ise önemsiz $(p>0,05)$ olduğu tespit edilmiştir. 90. gündeki yaşama gücüne cinsiyetin etkisi önemli $(p<0,01)$, doğum y1lı, doğum mevsimi ve ana yaş1 etkisinin ise önemsiz $(p>0,05)$ olduğu bulunmuştur.

\section{Buzağı Bakımı ve Yönetimi}

Afyonkarahisar merkez ve ilçelerinde ziyaret edilen 25 işletmede Simental, Holştayn ve Esmer 1rklarının bulunduğu ve yaygin olarak Simental'in tercih edildiği belirlenmiştir. Etçi-sütçü kombine verimli bir ırk olan Simental irkının Afyonkarahisar'da yoğun olarak yetiştirildiği görülmektedir. Bu durum 1 rkın besi kabiliyetinin yanında tatminkâr süt verimine sahip olmasından kaynaklanmış olabilir.

Düve ve ineklerin tohumlanmasinda işletmelerin 23 'ü suni tohumlama, 2'si ise doğal aşım yapmaktadır. Buzağıların analarından ayrılması ise bir işletme hariç geri kalanında 1-12 saat içinde, bir işletmede ise 3 gün sonra yapıldığı tespit edilmiştir. Buzağıların annelerinden erken ayrilması ile anneden geçebilecek hastalıklar önlenmiş olmaktadır. İşletmelerde buzağılara kolostrumun doğumdan sonraki ilk 1-2 saat içinde verildiği ve 3 gün süreyle günde 2-3 litre olmak üzere 2-4 kez/gün kolostrum içirildiği belirlenmiştir. Tümer (1998), yeni doğan buzağiya kolostrumun ilk iki saat içinde en az 2 litre, ilk üç gün ise kolostrum veya bunu takip eden geçiş sütünden günde 3,5 - 4 litre olmak üzere günde 3-4 öğünde içirilmesi gerektiğini ifade etmiştir. İşletmelerde buzağılara kolostrum verilme zamaninın uygun olduğu görülmektedir. Buzağılara verilen kolostrumun kalitesinin tespitine ilisskin bir uygulamanın yapılmadığı tespit edilmiştir. Bu durum işletmeler için riskli olup düşük kaliteli kolostrumun yaşama gücünü düşürebileceği değerlendirilmektedir. Buzağılarda göbek kordonu dezenfeksiyonunun doğumdan sonraki ilk 3 saat içerisinde olmak üzere genellikle 3 gün süreyle günde $2 \mathrm{kez}$ yapıldı̆̆ ifade edilmiştir. Patojen mikroorganizmaların göbek kordonu yoluyla bulaşabildiği ve bulaşmayı önlemek için göbek kordonunun doğum sonrası ilk 3 günde 12 saat arayla dezenfeksiyonunun yapılmasinın önemli olduğu bildirilmektedir (Anonim, 2019). Bu çalışmanın yürütüldüğü işletmelerde göbek kordonunun dezenfeksiyonuna önem verildiği tespit edilmiştir. Nitekim işletmelerin kayıtlarında göbek kordonu enfeksiyonuna rastlanmamıştır.

Bu çalışmanın yürütüldüğü işletmelerdeki buzağıların, yirmi iki işletmede seyyar buzağı kulübelerinde, üç işletmede ise bireysel kapalı bölmelerde barındırıldığ1, buzağ1 bölmelerinde kullanılan altlk tipinin ise on dokuz işletmede sap, iki işletmede odun talaşı ve dört işletmede ise 1zgara bulunduğu tespit edilmiştir. Buzağı bölmelerinde kullanılan altlı̆̆ın değişim sıklığı genellikle üç günde bir kez, bir işletmede yedi günde bir ve bir işletmede ise otuz günde bir yapılmaktadır. Moore ve ark. (2007) buzağıların bireysel kulübelerde barındirilmasinin temel amacinin hastaliklarin yayılmasını önlemek olduğunu, buzağı ishallerine neden olan patojenlerin yayılması bireysel kulübelerde daha yavaş olarak gerçekleştiğini ifade etmektedir. 
Ziyaret edilen işletmelerde bireysel kulübelerin kullanılması ve bu kulübelerin yetiştirme koşullarına uygun olması ișletmeler açısından önemli bir avantaj olarak değerlendirilmektedir.

Buzağıların sütle besleme döneminde üç işletmede sadece süt, diğerlerinde ise süt ile birlikte (7-30 gün sonra) kesif ve kaba yem verildiği tespit edilmiştir. Sütle besleme döneminde verilen besinin öğün sayısı, bir işletmede 3 ögün diğerlerinde 2 öğün olduğu ve sütle besleme için ise biberon kullanıldığı belirlenmiştir. İşletmelerde buzağıların sütle besleme süresi 60-90 gün arasında değişmektedir. İşletmelerde seyyar kulübe suluklarının kullanıldığı tespit edilmiştir. Araştırmanın yürütüldüğü işletmelerde buzağıların on işletmede gözlem ve kamera ile izlendiği, on beş işletmede ise sadece gözlem yoluyla takip edildiği tespit edilmiştir. Buzağıların günlük takiplerini kamera ve gözlem yöntemlerinin birlikte yapılmasinın yaşanabilecek sorunlarda daha erken müdahale imkânı sağlayacaktır. İşletmelerde aydınlatma olarak projektör, floresan ve LED aydinlatma kullanılmaktadır. İşletmelerin aydınlatma tercihlerinin yeterli olduğu düşünülmektedir.

\section{Buzağılarda Yaşama Gücü ve Etkileyen Faktörler} Araştırmanın yürütüldüğü işletmelerde 2016 ve 2017 y1llarında doğan Simental buzağıların 30., 60., 75. ve 90. günde yaşama gücü genel ortalaması sırasıla; \% 92,$0 ; \%$ 89,6; \% 87,4 ve \% 85,7 olarak tespit edilmiştir. Bu değerler (30. ve 60.gün yaşama gücü), Kaygisız ve Harmandar (2018) tarafindan yapılan çalışma $(\% 87,6)$ dışında bazı araştırmalarda Simental buzağılar için bildirilen değerlerden $(\% 92,0-98,8)$ daha düşüktür (Deliömeroğlu ve ark. 1995, Akbulut 1998, Koçak ve ark. 2008). Yaşama gücü arasındaki farklılıkların işletme koşullarından kaynaklandı̆̆1 düşünülmektedir. Nitekim diğer araştırmaların önemli bir kısmı Tarım ve Orman Bakanlığına bağlı işletmelerde yürütülmüştür. Bu çalışma ise yetiştirici koşullarında yapılmıştır.

Simental buzağılarda yaşama gücüne 30. günde işletme ve doğum mevsiminin, 60. günde işletme, doğum mevsimi ve ana yaşının, 75. günde işletme, doğum mevsimi, cinsiyet ve ana yaşının, 90. günde işletme, doğum mevsimi ve ana yaşının etkisinin önemli $(\mathrm{p}<0,05 ; \mathrm{p}<0,01)$ olduğu tespit edilmiştir. Bu çalışmada işletme faktörünün buzağılarda yaşama gücüne etkisi incelendiğinde bütün dönemlerde en düşük yaşama gücü 6 numaralı işletmede, en yüksek ise 4 numaralı işletmede doğan Simental buzağılarda tespit edilmiştir. Bu durum özellikle 6 numaralı işletmede gebe düve ile yetiştirmeye başlanması, kolostrum kalitesinin düşük olması ve buzağ1 yönetimindeki aksaklıklardan kaynaklanmış olabilir. Ayrıca işletmelerdeki bakım, besleme ve buzağı idaresindeki farklılıklarında yaşama gücünü etkilediği değerlendirilmektedir. Simental buzağılarda yaşama gücü, doğum mevsimi bakımından incelendiğinde, ilkbahar ve yaz mevsiminde doğan buzağılarda yaşama gücü sonbahar ve kış mevsiminde doğanlara göre daha yüksek olmuştur. Doğum mevsiminin yaşama gücüne etkisinin Koçak ve ark. (2008)'nın bildirişlerinin aksine önemli $(p<0,05 ; \mathrm{p}<0,01)$ olduğu tespit edilmiştir. Ayrıca Ünal ve ark. (2001) tarafından Simental buzağılarda yapılan bir araştırmada 3 aya kadar yaşama gücü tüm mevsimlerde doğan buzağılarda \% 100 olarak bildirilmiş olup buzağ1 ölümleri 3-6 ay arasında gerçekleştiği ifade edilmiştir.

Simental buzağılarda yaşama gücü cinsiyet bakımından değerlendirildiğinde incelenen bütün dönemlerde dişi buzağıların yaşama gücünün erkeklerden daha yüksek olduğu ve aralarındaki farklilikların sadece 75. günde istatistiki olarak önemli $(p<0,05)$ olduğu tespit edilmiştir. Koçak ve ark. (2008) tarafindan Holştayn, Simental ve Esmer 1rk buzağılarda yapılan bir araştırmada da benzer bulgular bildirilmiştir. Dişi buzağılarda yaşama gücünün daha yüksek olması damızlık adayı olan dişi buzağılara daha fazla özen gösterilmesinden kaynaklanmış olabilir.

Simental buzağılardaki yaşama gücüne ana yaşının etkisi incelendiğinde 60., 75. ve 90. günde buzağıların yaşama gücü ortalamaları arasındaki farklilıkların istatistiki olarak önemli $(\mathrm{p}<0,05 ; \mathrm{p}<0,01)$ olduğu, 4 yaşlı ineklerden doğan buzağıların yaşama gücü en düşük, 5 ve üzeri yaşlı ineklerden doğan buzağılarda ise en yüksek olduğu tespit edilmiştir.

$\mathrm{Bu}$ çalışmada Holştayn buzağılardaki yaşama gücü genel ortalamalar1 30., 60., 75. ve 90. günde sirasiyla; $\%$ 91,8; \% 91,8; \% 91,8 ve \% 89,3 olarak tespit edilmiştir. Bu değerler, Karakaş (2002) tarafindan yapılan bir çalışma $(\% \quad 85,9)$ ile Kaygısız ve Harmandar (2018)'ın bildirimlerinden (\% 89,7) yüksek, bazı çalışmalarda Holştayn buzağılar için bildirilen yaşama gücü değerlerinden (\%92,6-\% 97,0) ise daha düşük olmuştur (Başpınar ve ark. 1998, Koçak ve ark. 2007, Bayrıl ve Y1lmaz 2010, Ayaşan ve ark. 2016). Bu durum, araştırmaların yürütüldüğü işletme koşullarındaki farklılıklardan kaynaklanmış olabilir.

Holştayn buzağılarda 30., 60. ve 75. gündeki yaşama gücüne cinsiyet ve doğum mevsiminin etkisi önemli $(p<0,05 ; p<0,01)$, doğum y1lı ve ana yaşının ise önemsiz ( $>0,05)$, 90. gündeki yaşama gücüne cinsiyetin etkisi önemli $(p<0,01)$, doğum y1lı, doğum mevsimi ve ana yaşı etkisinin ise önemsiz ( $p>0,05)$ olduğu tespit edilmiştir. Bu çalışmada Holştayn buzağilardaki yaşama gücü doğum mevsimi bakımından incelendiğinde ilkbahar ve yaz mevsiminde doğanların yaşama gücünün sonbahar ve k1ş mevsiminde doğanlara göre daha yüksek olmuştur. Bu çalışmadaki bulgulara benzer şekilde Başpınar ve ark. (1998)'da kış aylarında doğan buzağıların yaşama gücünün diğger mevsimlerde doğanlara göre daha 
düşük olduğunu bildirmiştir. Bu araştırmadan farklı olarak bazı çalışmalarda buzağılama mevsiminin yaşama gücüne etkisinin istatistiki olarak önemli olmadığı bildirilmiştir (Koçak ve ark. 2007, Bayrıl ve Yılmaz 2010). Holştayn dişi buzağılarda yaşama gücü, incelenen tüm dönemlerde erkeklere göre daha yüksek bulunmuştur. Benzer şekilde Holştayn buzağılarda yapılan bazı araştırmalarda dişi buzağılarda yaşama gücünün erkeklerden daha yüksek olduğu bildirilmiştir (Koçak ve ark. 2007, Koçak ve ark. 2008, Yüceer ve Özbeyaz 2010; Ayaşan ve ark. 2016). Dişi buzağılarda yaşama gücünün daha yüksek olması damızlık adayı olan diși buzağılara daha fazla özen gösterilmesinden kaynaklanmış olabilir.
Holştayn buzağılardaki yaşama gücüne ana yaşının etkisi incelendiğinde 2 yaşlı ineklerden doğan buzağılarda yaşama gücü en düşük, 4 yaşlı ineklerden doğan buzağılarda ise en yüksektir. Ana yaş1 faktörünün buzağılarda 30., 60., 75. ve 90. gün yaşama gücüne etkisi istatistiki yönden önemsiz ( $\mathrm{p}>0,05)$ olmuştur. Benzer şekilde Koçak ve ark. (2008)'da ana yaşının buzağılarda yaşama gücüne etkisinin istatistiki düzeyde önemli olmadığını bildirmiştir. Ayrıca Bayrıl ve Yılmaz (2010), ana yaşının Holştayn buzağılarda sütten kesimde (2. ay) yaşama gücü üzerine etkisinin önemli ( $\mathrm{p}<0,01)$ olduğunu ifade etmektedir.

Tablo 1. Simental Buzağılarda Yaşama Gücüne Ait Ortalamalar ve Standart Hatalar1

Table 1. Least squares means and standard errors for survival rate in Simmental calves
30. gün
60. gün
75. gün
90. gün

\begin{tabular}{|c|c|c|c|c|c|c|}
\hline Faktörler & & $\mathbf{n}$ & $\overline{\mathbf{X}} \pm \mathbf{S}_{\bar{x}}$ & $\overline{\mathbf{X}} \pm \mathbf{S}_{\bar{x}}$ & $\overline{\mathbf{X}} \pm \mathbf{S}_{\bar{x}}$ & $\overline{\mathbf{X}} \pm \mathrm{S}_{\overline{\mathrm{x}}}$ \\
\hline & $\mu$ & 400 & $0,920 \pm 0,021$ & $0,896 \pm 0,023$ & $0,874 \pm 0,025$ & $0,857 \pm 0,025$ \\
\hline \multirow[t]{8}{*}{ İşletme } & & & $* *$ & $* *$ & $* *$ & $* *$ \\
\hline & 1 & 25 & $0,928 \pm 0,053$ a & $0,921 \pm 0,058^{\mathrm{a}}$ & $0,885 \pm 0,063^{a}$ & $0,873 \pm 0,065^{a}$ \\
\hline & 2 & 81 & $0,940 \pm 0,034^{\text {a }}$ & $0,921 \pm 0,037^{\mathrm{a}}$ & $0,921 \pm 0,040^{\mathrm{a}}$ & $0,908 \pm 0,041^{\mathrm{a}}$ \\
\hline & 3 & 29 & $0,930 \pm 0,058^{\text {a }}$ & $0,869 \pm 0,063^{\mathrm{a}}$ & $0,824 \pm 0,068^{\mathrm{ab}}$ & $0,809 \pm 0,070^{\mathrm{ab}}$ \\
\hline & 4 & 92 & $0,984 \pm 0,031$ a & $0,964 \pm 0,034^{a}$ & $0,961 \pm 0,037^{\mathrm{a}}$ & $0,960 \pm 0,038^{a}$ \\
\hline & 5 & 58 & $0,976 \pm 0,041$ a & $0,956 \pm 0,045^{\mathrm{a}}$ & $0,948 \pm 0,048^{a}$ & $0,925 \pm 0,050^{a}$ \\
\hline & 6 & 77 & $0,813 \pm 0,041^{\mathrm{b}}$ & $0,785 \pm 0,044^{\mathrm{b}}$ & $0,756 \pm 0,048^{\mathrm{b}}$ & $0,735 \pm 0,050^{\mathrm{b}}$ \\
\hline & 7 & 38 & $0,866 \pm 0,043^{\mathrm{ab}}$ & $0,854 \pm 0,047^{\mathrm{ab}}$ & $0,821 \pm 0,050^{\mathrm{ab}}$ & $0,791 \pm 0,052^{\mathrm{ab}}$ \\
\hline \multicolumn{7}{|l|}{ Doğum Y1lı } \\
\hline & 2016 & 104 & $0,934 \pm 0,031$ & $0,910 \pm 0,033$ & $0,882 \pm 0,036$ & $0,874 \pm 0,037$ \\
\hline & 2017 & 296 & $0,906 \pm 0,021$ & $0,882 \pm 0,023$ & $0,865 \pm 0,025$ & $0,841 \pm 0,026$ \\
\hline \multirow[t]{3}{*}{ Doğum Mevsimi } & & & $*$ & $* *$ & $* *$ & $* *$ \\
\hline & Sonbahar-K1ş & 232 & $0,885 \pm 0,026^{\mathrm{b}}$ & $0,852 \pm 0,028^{\mathrm{b}}$ & $0,824 \pm 0,031^{\mathrm{b}}$ & $0,801 \pm 0,032^{\mathrm{b}}$ \\
\hline & İlkbahar-Yaz & 168 & $0,954 \pm 0,026^{a}$ & $0,939 \pm 0,028^{\mathrm{a}}$ & $0,924 \pm 0,031^{\mathrm{a}}$ & $0,914 \pm 0,032^{\mathrm{a}}$ \\
\hline \multirow[t]{3}{*}{ Cinsiyet } & & & & & $*$ & \\
\hline & Erkek & 223 & $0,905 \pm 0,024$ & $0,878 \pm 0,026$ & $0,844 \pm 0,021^{\mathrm{b}}$ & $0,834 \pm 0,030$ \\
\hline & Dişi & 177 & $0,934 \pm 0,025$ & $0,914 \pm 0,027$ & $0,903 \pm 0,029^{a}$ & $0,881 \pm 0,030$ \\
\hline \multirow[t]{5}{*}{ Ana Yaş1 } & & & & $*$ & $*$ & $* *$ \\
\hline & 2 & 217 & $0,938 \pm 0,021$ & $0,933 \pm 0,023^{a}$ & $0,912 \pm 0,025^{\mathrm{ab}}$ & $0,911 \pm 0,026^{a}$ \\
\hline & 3 & 82 & $0,938 \pm 0,032$ & $0,899 \pm 0,035^{a}$ & $0,853 \pm 0,037 \mathrm{ab}$ & $0,844 \pm 0,039 \mathrm{ab}$ \\
\hline & 4 & 24 & $0,827 \pm 0,055$ & $0,778 \pm 0,059^{\mathrm{b}}$ & $0,769 \pm 0,064^{\mathrm{b}}$ & $0,728 \pm 0,067^{b}$ \\
\hline & $5 \leq$ & 77 & $0,976 \pm 0,037$ & $0,972 \pm 0,040^{\mathrm{a}}$ & $0,962 \pm 0,044^{a}$ & $0,948 \pm 0,045^{a}$ \\
\hline
\end{tabular}

$*: \mathrm{p}<0,05 ;{ }^{* *}: \mathrm{p}<0,01$

a, b.: Aynı sütunda her alt grupta farklı harfleri taşıyan ortalamalar arası farklılıklar önemlidir $(\mathrm{p}<0,05)$. 
Tablo 2. Holştayn Buzağılarda Yaşama Gücüne Ait Ortalamalar ve Standart Hataları

Table 2. Least squares means and standard errors for survival rate in Holstein calves

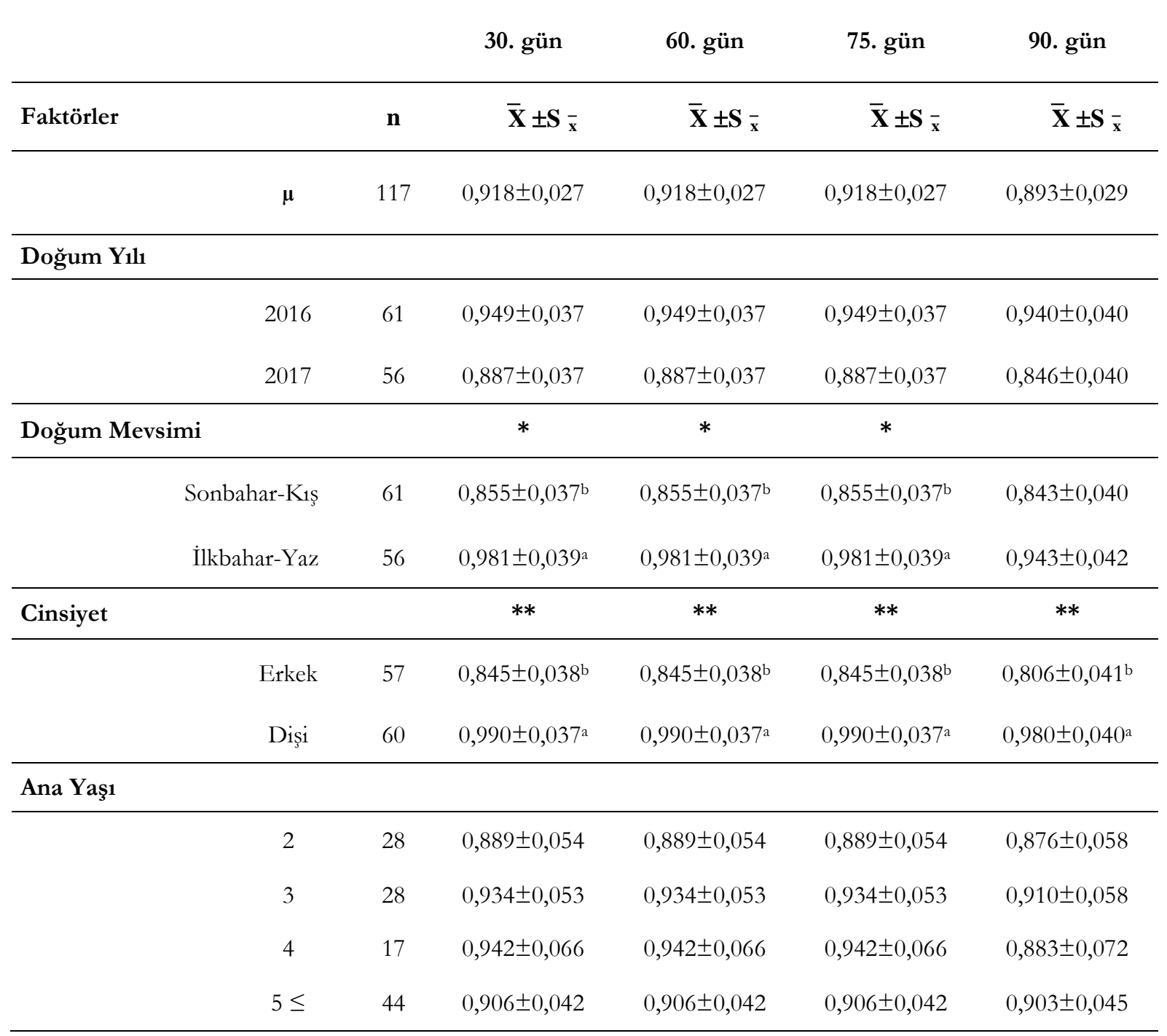

$*: \mathrm{p}<0,05 ;{ }^{* *}: \mathrm{p}<0,01$

a, b.: Aynı sütunda her alt grupta farklı harfleri taşıyan ortalamalar arası farklılıklar önemlidir $(\mathrm{p}<0,05)$.

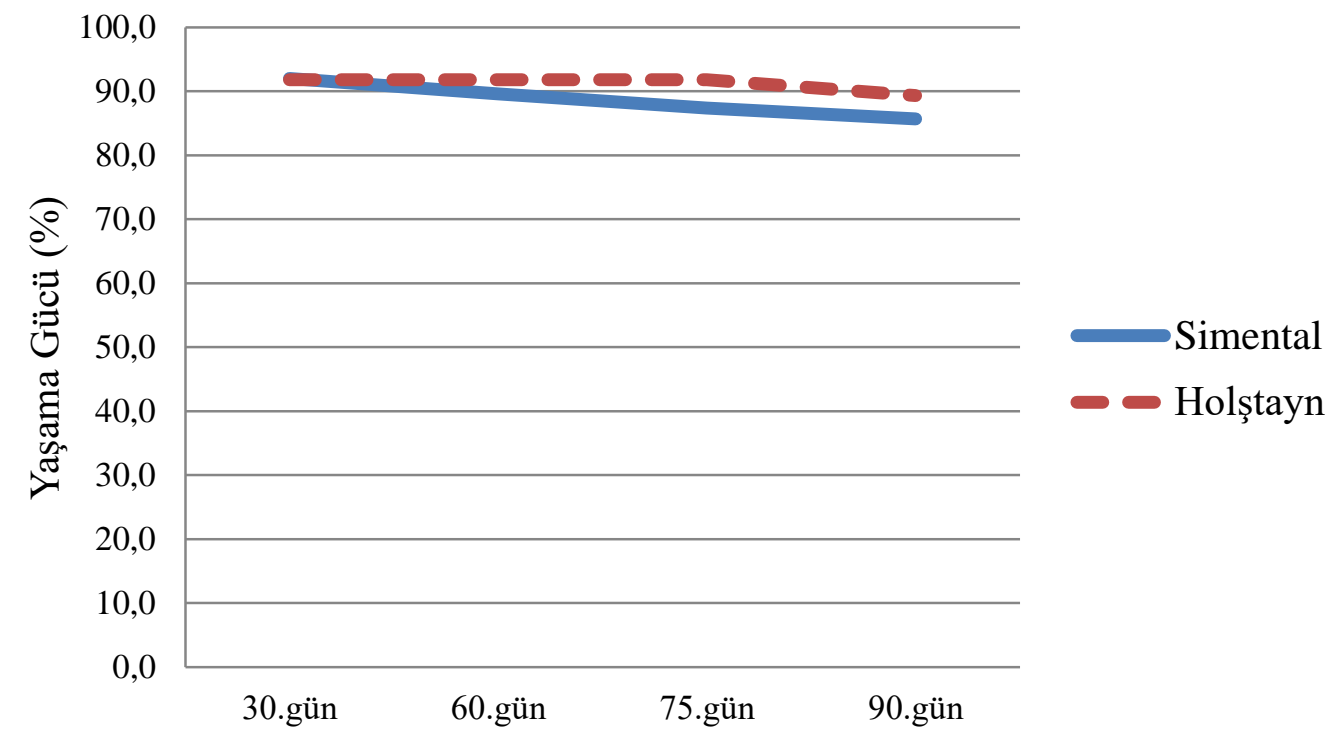

Şekil 1. Simental ve Holştayn Buzağılarda Yaşama gücü değerleri

Figure 1. Survival rate in Simmental and Holstein calves 


\section{SONUÇ}

Sonuç olarak incelenen ișletmelerde Simental ve Holştayn buzağıların yaşama gücü genel ortalaması 30.günde \% 92,0 ve \% 91,8 düzeyinde, 90 .günde ise \% 85,7 ve \% 89,3 olarak tespit edilmiştir. İşletmelerde buzağı bakım ve yönetimine önem verildiği, Simental ve Holştayn buzağılarda yaşama gücünün optimal verimlilik ve ideal değer bakımından düşük olduğu, sütle besleme döneminde kolostrum kalitesi ve yönetimine dikkat edilmesi gerektiği kanaatine varılmıştır.

\section{TEŞEKKÜR}

Bu çalsma Kemal Yuldirn'in yükesek lisans terinden özetlenmis olup Afyon Kocatepe Üniversitesi Hayvan Deneyleri Yerel Etik Kurulu'nun 24.10.2017 tarih ve 49533702/166 saynl yazıst ile etike prensiplere uyumlu bulunmustur. Yazarlar arastrmann yürütülmesinde yardımlarndan dolayn işletme sahiplerine teşekekür ederler.

\section{KAYNAKLAR}

Akbulut Ö. Simental sığırların Türkiye'de verim performansı üzerine bir değerlendirme. Atatürk Üniversitesi Ziraat Fakültesi Dergisi, 1998; 29 (1): 43-49.

Akçapınar H, Özbeyaz C. Hayvan yetiştiriciliği temel bilgileri. Kariyer matbaacillk, Ankara, 1999.

Anonim. Önsöz, Buzağ1 Kayıplar1 Sempozyumu. 21-22 Aralık 2017, Kirıkkale.

Anonim. Buzağı Bakım ve Beslenmesi. Erişim: [https://www.tarimorman.gov.tr/HAYGEM/Belgeler/ Hayvanc $\% \mathrm{C} 4 \% \mathrm{~B} 11 \% \mathrm{C} 4 \% \mathrm{~B} 1 \mathrm{k} / \mathrm{B} \% \mathrm{C} 3 \% \mathrm{BCy} \% \mathrm{C} 3 \% \mathrm{BCkb}$ a $\%$ C5\% $\%$ F $\% 20$ Hayvanc $\% C 4 \% B 11 \% C 4 \% B 1 k / 2016 \% 20$ Y\%C4\%B11\%C4\%B1/Buza $\% C 4 \% 9 F \% C 4 \% B 1 \% 20 \mathrm{Bak}$ $\% \mathrm{C} 4 \% \mathrm{~B} 1 \mathrm{~m} \% 20 \mathrm{ve} \% 20 \mathrm{Beslenmesi.pdf]} \quad$ Erişim Tarihi:21.02.2019.

APHIS. Mortality of Calves and Cattle on U.S. Beef Cow-calf Operations,May2010.

Erişim:[https://www.aphis.usda.gov/animal_health/nah ms/beefcowcalf/downloads/beef0708/Beef0708_is_Mor tality.pdf] Erişim Tarihi: 05.01.2019.

Ayaşan T, Hızlı H, Asarkaya A, Coşkun MA. Siyah Alaca buzağılarda büyüme performansı ve yaşama gücü. Türk Tarım ve Doğa Bilimleri Dergisi, 2016; 3 (3): 223-228.

Azizzadeh M, Shooroki HF, Kamalabadi, AS, Stevenson MA. Factors affecting calf mortality in Iranian Holstein dairy herds. Preventive Veterinary Medicine, 2012; 104 (3-4): 335-340.

Başpınar H, Oğan M, Batmaz ES, Balcı F, Karakaş E, Baklacı C. Esmer ve Holştayn buzağıların büyüme ve yaşama gücüne etki eden bazı çevresel faktörler. Lalahan Hayvancllık Araştırma Enstitüsü Dergisi, 1998; 38 (2): 1931.

Bayrıl T, Yılmaz O. Kazova Vasfi Diren Tarım İşletmesinde yetiştirilen siyah alaca buzağılarda büyüme performansı ve yaşama gücü. Yüzüncü Yıl Üniversitesi Veteriner Fakültesi Dergisi, 2010, 21 (3): 169 - 173.

De Amicis I, Veronesi, MC, Robbe D, Gloria A, Carluccio A. prevalence, causes,resolution and consequences of bovine dystocia in Italy. Theriogenology, 2017, 107: 104-108.
Deliömeroğlu Y, Alpan O, Bakır A. İthal Simental sığırların Kazova tarım işletmesi şartlarında büyüme ve yaşama gücü. Lalahan Hayvancılık Araştırma Enstitüsü Dergisi, 1995, 35 (3-4): 1-15.

Gates MC. Evaluating there productive performance of British beef and dairy herds using national cattle movement records. Vet. Rec., 2013, 173 (20): 499.

Gulliksen S M, Lie KI, Loken T, Osteras O. Calf mortality in Norwegian dairy herds. Journal of Dairy Science, 2009, 92 (6): 2782-2795.

Haile-Mariam M. Factors influencing preweaning calf survival rate and cow productivity index in Ethiopian Boran Cattle. 6th International Committee for World Congress on Genetics Applied to Livestock Production, Armidale, NSW Australia, 1998, pp.203-206.

Karakaş E. Bursa-Yenişehir ilçesinde yetiştirilen Holştayn buzağıların doğum ağırlığı, sütten kesim yaşı, süt tüketimleri ve yaşama güçleri. Uludağ Univ J Fac Vet Med, 2002, 21: 77-81.

Kaygısız A, Harmandar A. Kahramanmaraş ilindeki iki özel işletmede kültür ırkı sığırların adaptasyon düzeylerinin sigorta hasar tazminatı alma kriteri bakımından karşılaştırılması. KSÜ Tarım ve Doğa Dergisi, 2018, 21 (2): 215-219.

Koçak S, Tekerli M, Özbeyaz C, Yüceer B. Environmental and genetic effects on birth weight and survival rate in Holstein Calves. Turkish Journal of Veterinary and Animal Sciences, 2007, 31 (4): 241-246.

Koçak S, Tekerli M, Özbeyaz C, Demirhan İ. Lalahan Merkez Hayvancılık Araştırma Enstitüsünde yetiştirilen Holştayn, Esmer ve Simental sığırlarda bazı verim özellikleri. Lalahan Hayvancilık Araştırma Enstitüsü Dergisi, 2008, 48 (2): $51-57$

Moore DA, Heaton K, Poisson S, Sischo WM. Dairy calf housing and environment. The Science Behind Housing and on-Farm Assessments. National Integrated Food Safety Initiative 2007-01877.

Özyürek S, Koçyiğit R, Tüzemen N. Buzağı yetiştiriciliğinde buzağ1 barınaklarının önemi. Alınteri Zirai Bilimler Dergisi, 2013, 24: 46-52.

Raboisson D, Delor F, Cahuzac E, Gendre C, Sans P, Allaire G. Perinatal, neonatal, and rearing period mortality of dairy calves and replacement heifers in France. Journal of Dairy Science, 2013, 96 (5): 2913-2924.

Riley DG, Chase CC, Olson TA, Coleman SW, Hammond AC. Genetic and nongenetic influences on vigor at birth and preweaning mortality of purebred and high percentage Brahman Calves. J. Anim. Sci., 2004, 82: 15811588.

SPSS Inc. PASW Statistical Program. Version 18.0.0., 2009, Chicago, IL, USA: SPSS Inc.

Tümer S. Buzağıların bakım ve beslenmesi. Ege Tarımsal Araştırma Enstitüsü Müdürlüğü. Çiftçi Broşürü, 1998, No: 87.

Ünal N, Ertuğrul O, Alpan $\mathbf{O}$. Growth and survival of Simmental calves reared outdoors in individual hutches. Turkish Journal of Veterinary and Animal Sciences,2001,25:789-795.

Yüceer B, Özbeyaz C. Kolostrum almış buzağılarda bağışıklığın, büyüme, hastalık insidansı ve yaşama gücü üzerine etkisi. Ankara Üniversitesi Veteriner Fakültesi Dergisi, 2010; 57: 185-190. 